\title{
A Strategic Thinking on Multi-Level Business Development in Wellness Foods
}

\author{
Rich C. Lee ${ }^{1,2}$ \\ ${ }^{1}$ Department of Information Management, National Sun Yat-sen University, Kaohsiung, Chinese Taipei; ${ }^{2}$ System Technology Group, \\ IBM, Chinese Taipei. \\ Email: rich.chih.lee@gmail.com
}

Received March 24 ${ }^{\text {th }}, 2012$; revised April 18 ${ }^{\text {th }}$, 2012; accepted May $16^{\text {th }}, 2012$

\begin{abstract}
More people are accepting the self-care concept in natural health regimens as the complementary and alternative medicine has become a key driver for wellness foods industry business. Many wellness food companies rely on multi-level marketing — directly selling products through individuals' social networks-frothier business development. Few people are able to succeed in promoting this complex perception-change about the benefits of natural health regimens to consumers and making this as a steady income stream. Current, the success of direct-selling model requires the individuals who possess similar personal attributes and capabilities. This paper argues a novel way-a holistic approach—to elaborate the strategy and to give the business development guidelines to the wellness food industries.
\end{abstract}

Keywords: Multi-Level Marketing; Service Science Management and Engineering; System Dynamics

\section{Introduction}

More people believe that taking wellness foods will benefitthe outcome of self-care in recent years. The market size of wellness foods are noticeably increased for the past decade in the globe. Facing the critical challenge -the aging problem; people are willing to pay more to improve their health. The economy growth gives a warmbed for wellness food business incubation. Many wellness food companies rely on the multi-level direct-selling model for business development. To make this work, there are six key elements in viral marketing strategy: 1 ) gives away products or services; 2 ) provides for effortless transfer to others; 3) scales easily from small to very large; 4) exploits common motivations and behaviors; 5) utilizes existing communication networks; and 6) takes advantage of others' resources [1]. However, such a viral marketing approach - a strategy that encourages individuals to pass on a marketing message to others, creating the potential for exponential growth in the message's exposure and influence-assumed that each business developer possesses the same personal attributes and capabilities on the market penetration. Currently, the common business development practice in wellness food companies is to 1) offer trial products to the consumers; 2) introduce a simple business proposal to the potential entrants; 3) inspire the resellers to expanding their social networks deeper; 4) implicate the potential outcomes to health by applying medical theories and findings; and 5) motivate the potential consumers to purchase the products by sharing the successful stories in improving health and the career development as well. These wellness food companies are continuously investing lots of efforts and time in intensive training on product knowledge transferring and the morality inspiration, because they believe that the resellers can meet the sales goals if they possess sufficient product knowledge and the abilities in developing their social networks. Many resellers cannot survive in this business model requiring high-motivation. The frustration comes from many facets. In generally speaking; the resellers' income depends on the sales bonus, because many multi-level marketing companies do not pay the base salary to the resellers, if the product cannot push to the market quickly, the income will be unsteady. On the other hand, their personal attributes limit the business development speed; only few people are good at all business required aspects, such as communicating to others, explaining the product benefits, and with broad medical information. Apparently, the current practice might have founded on a wrong assumption - the resellers are uniform as selling machines-observed from the high mortality rate of newbies in this business. Multi-level marketing is a powerful means for both marketers and recipients; through such a viral marketing approach, the marketers push the products to the people they can influence; and the recipients get more customer intimacy and service from the marketers too. In 
wellness food business, the consumers need more than just receiving the products but the sharing the self-care knowledge also. Therefore, the success of this business model hinges upon the recognition of the strong need for influencers to be viewed as knowledgeable helpers in the social network rather than as agents of the marketer [2].

This paper articulates the reasons behind and how to effectively improve the multi-level business development in wellness food industries.

\section{Research Design}

Different multi-level marketing wellness food companies have their unique products and bonus plans. They are also facing the various phases in business development. Furthermore, most resellers in this business have multiple roles at the same time; they are the product consumers, make tactics in business development, and are the mentors and recruiters of newbies. To disclose the obstacles of multi-level marketing business and infer useful strategies to these companies requires deeper investigation from different perspectives.

The qualitative research is a type of scientific research. In general terms, scientific research consists of an investigation that: 1) seeks answers to a question; 2) systematically uses a predefined set of procedures to answer the question; 3) collects evidence; 4) produces findings that were not determined in advance; and 5) produces findings that are applicable beyond the immediate boundaries of the study. The qualitative research is especially effective in obtaining culturally specific information about the values, opinions, behaviors, and social contexts of particular populations. The strength of qualitative research is instability to provide complex textual descriptions of how people experience given research issue. It provides information about the "human" side of an issue-that is, the often contradictory behaviors, beliefs, opinions, emotions, and relationships of individuals. Qualitative methods are also effective in identifying intangible factors, such as social norms, socioeconomic status, gender roles, ethnicity, and religion, whose role in the research issue may not be readily apparent. When used along with quantitativemethods, qualitative research can help us interpret and better understand the complex reality of a given situation and the implications of quantitative data. Although findings from qualitative data can often be extended to people with characteristics similar to those in the study population, gaining a rich and complex understanding of a specific social context or phenomenon typically takes precedence over eliciting data that can be generalized to other geographical areas or populations. In this sense, the quailtative research differs lightly from scientific research in general [3].

The objectives of data analysis in qualitative research should be able to disclose the following aspects: 1) what are the core meanings about the analysis, do these data reveal better understanding or imply a theory behind the phenomenon? 2) What are the most helpful viewpoints that answer the research questions? and 3) how to present the research findings [4].The system dynamics (SD) approach with its causal philosophy and purpose of gaining deep insight into the working of a system places heavy emphasis on "looking within the system"; it contains mainly six problem-solving steps throughout the methodology operates, such as: 1) problem identification and definition, 2) system conceptualization, model formulation, 3) simulation and validation of the model, 4) policy analysis and improvement, policy implementation [5].

Figure 1 illustrated the research process. This research process takes advantage of two powerful methods in deep disclosing phenomenon, qualitative research and system dynamics. In system dynamics, a causally-closed system is one in which the causes creating the behavior of inter-

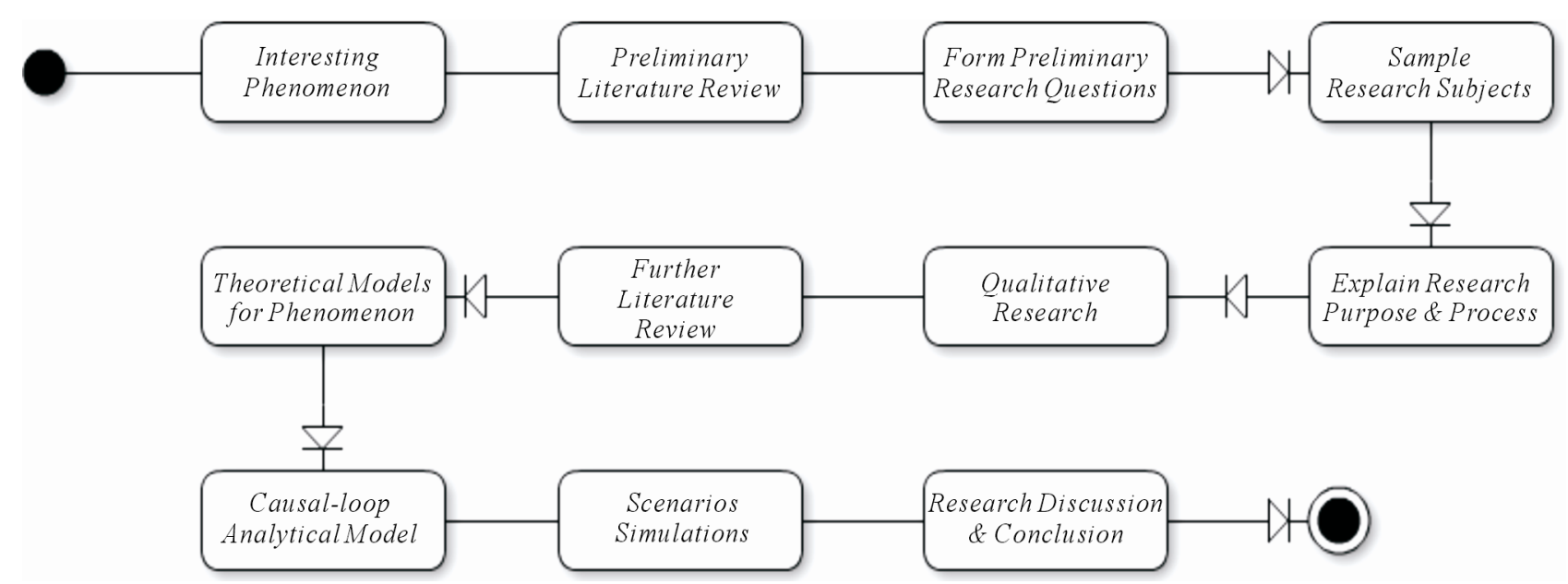

Figure 1. The research design. 
est lie within the system. A causally-closed system still is open in the sense that it can receive material, energy, random disturbances, and test inputs from outside the boundary [6]. This research relies on the qualitative research to form the conceptual model used in system dynamics for further phenomenon articulation. Most of all, by using the system dynamics tool, the researcher can give conditional parameters to see what the model behaves later to form the recommendations or policy to move the outcome towards more positive direction.

There search process begins with the interesting phenomenon observed, reviewing the literature to see if previous studies could explain the phenomenon or not, a more clearer picture of research questions are formed, choosing appropriate research subjects and explain why and how the research will be conducted, undertaking a series of qualitative activities, confirming the theoretical foundation of observed artifacts via further literature review, forming theoretical models to answer the research questions, developing causal-loop analytical model, simulating various scenarios for research implication and recommendations to practitioners.

\section{Case Study}

This paper chose two research subjects. Both companies use multi-level marketing as their primary tool of business development, offer the similar wellness products made of Reishi, and have their own farms and factories. Both research subjects claim that they are biological companies and have discovered vital bio-components extracted from the natural material-Reishi- to be able to improve the human immune system. One company has entered the market sooner than the other near two decades; the younger company claims that the major extract of their products was authorized from a national research agency.

Their business model is through individuals distributing the products. The selling discounts depend on the volume of product purchases and the rank of the resellers. The resellers with higher ranks get better discounts of products. The business model encourages the resellers to expand their personal distribution channels-the multilevel marketing — and share the profits generated by their descendent-resellers. The whole descendant structure is like a profit-sharing pyramid; the more levels of the structure and with more capable descendants, the better profit- sharing that the root-reseller will have. For those root- resellers who have exceeded the profit-sharing brackets will get extra bonus from their company.

The author visited both companies and observed their processes including: 1) product knowledge transferring, 2) experience sharing, and 3) morality building. He interviewed the participants from both companies including: 1) business managers, 2) senior resellers, 3) newbies, and 4) product lecturers. He also interviewed two focus-groups and participated the business development discussion meetings led by their root-resellers of both companies.

\section{Obstacles of Business Development}

Businesses do not operate in isolation, being complex and volatile is certain to business. Managers need to understand the impact that the surrounding business environment has on their own organization. The issues of multi-level marketing involve multiple related facets and thus cannot be articulated from silo perspectives. The STEP — social, technological, economic, and politicalmodel helps identifying the factors in the broader environment that will affect their business. The STEP frame work is a useful tool that helps managers thinking about current influences on their organization and possible future changes, it seeks to identify and assess the external drivers of change that will have an influence on the insurance marketplace and industry. The Social factors include trends that affect customers or employees: demographic changes, availability of skills, and so forth. The Technological factors include improved raw materials, better communication, and higher-quality equipment. The Economic factors include trends in people's employment status and incomes. The Political factors include company's policies, domestic governmental policies and the impact of new legislation. Based on the data analysis, the understanding of those factors that cause the business development obstacles were categorized by the STEP framework illustrated on Figure 2 and depicted the details as follows.

\subsection{Social Obstacles}

There are three major obstacles: 1) Poor Interpersonal Skills, 2) Less Self-Motivated and 3) Poor Teaming. The success of viral marketing depends on highly self-motivated persons with interpersonal skills to develop business. If the reseller has other income streams and does not pay more attention on business development, consequently the result will be less significant to his/her total income; this will further deteriorate the motivation. The resellers must take advantage of other resellers' capability to make the selling cycle shorter especially under the multi-level business model. The root-resellers developed descendants new sub-channels-within their social networks by chance. Each descendent-reseller has different personality and attributes; some are good at convincing the products; some are good at channel development; some even have no noticeable skills just with passion and prospects.

\subsection{Technological Obstacles}

There are three major obstacles: 1) Insufficient Product 


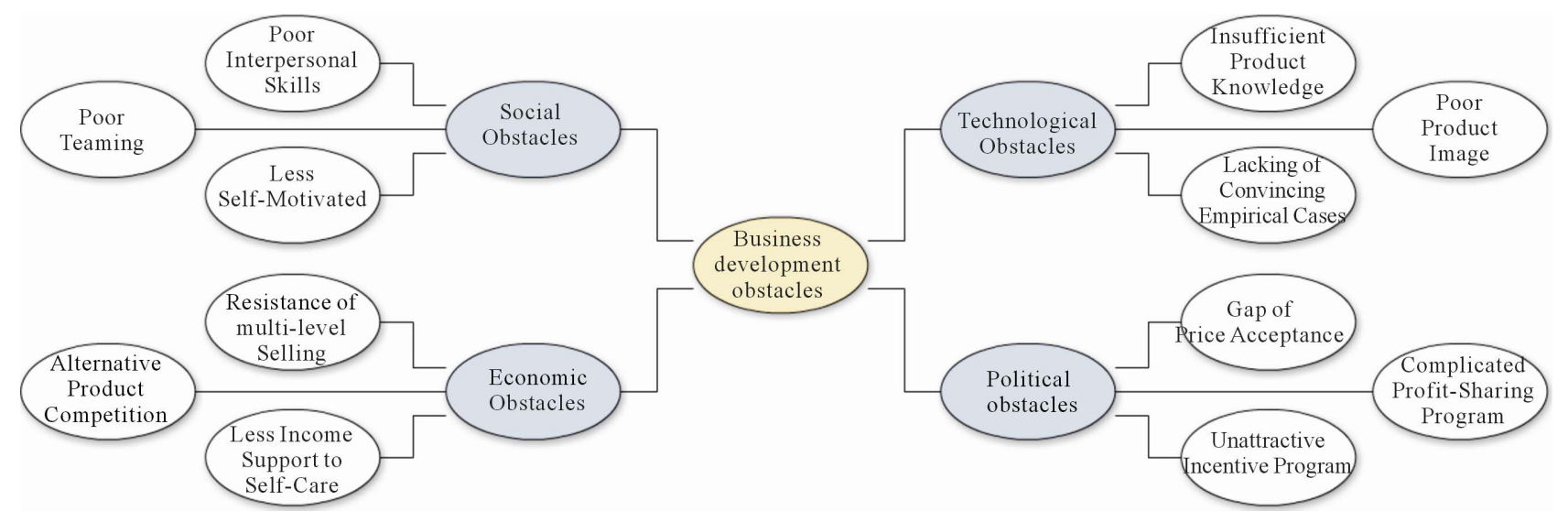

Figure 2. The STEP analysis of business development obstacles.

Knowledge, 2) Lacking of Convincing Empirical Cases, and 3) Poor Product Image. The potential outcomes of taking biological products are not easy to explain to consumers. Many supporting documents are medical and pharmaceutical research papers. Most significant ingredients of a biological product are named from special biochemical terms. This increases the gap of under standing to both reseller sand consumers as well. To accumulate product knowledge has some difficulty for non-biochemical background persons. Since wellness foods are not medicine, it is very hard to claim a cured-case was attributed to particular treatment. People are often skeptical in accepting a new concept that will improve health; there might be thousands of alternative solutions would do the job. When wellness product cost is considerably high, people will be more skeptical and hesitate in purchasing the products. A product with poor image may attributed to many reasons, despite of the price-performance and quality factor, the resellers have difficulty to push products into the market will also affect the image, simply just few people aware the products.

\subsection{Economic Obstacles}

There are three major obstacles: 1) Resistance of MultiLevel Selling, 2) Less Income Support to Self-Care, and 3) Alternative Product Competition. Many people have unpleasant experience or negative image on multilevel selling. When resellers are promoting the products or recruiting the descendants, people might reject the products simply because the business model is based on social networks. Wellness foods are products of nice-tohave. The consumers must have adequate financial capability in order to purchase these usually not-expensive products. Product's market differentiation also causes longer selling cycle in persuading the consumers about the uniqueness and superiority of the product against others.

\subsection{Political Obstacles}

There are three major obstacles: 1) Gap of Price Acceptance, 2) Unattractive Incentive Program, and 3) Complicated Profit-Sharing Program. Companies applying Multilevel Selling are more human psychological driven. The price of the products must be juicy enough to cover the profit sharing for all levels; this inevitably produces more gaps to consumers to accept the products. If the price was made more competitive, the reseller's incentive program would be less attractive to promote the products. The profit-sharing program determines the motivation; if the percentage is favor to the bottom level direct facing the consumers, the resellers will have less motivation to expand deeper level descendants; on the other hand, if the percentage is favor to upper levels, the resellers will spend more time in expanding the channels instead of promoting the products directly. The more complicated the profit-sharing rule is, the less attractive will be to the potential newbies.

\section{Causal-Loop Model and Scenario Simulations}

Improving Poor Teaming will mitigate the impact of Poor Interpersonal Skills and Less Self-Motivated. Shared cognition is a critical driver of team performance, especially in shared mental models, team situation awareness, and understanding communication as a fundamental component of how information is processed at the team level [7]. People expect getting positive reward after devoting efforts. Such causality orientation are general motivational orientations [8], thus less Self-Motivated is the most significant factor to Social Obstacles. Improving Insufficient Product Knowledge will mitigate the impact of Poor Product Image and Lacking of Convincing Empirical Cases. This implies that experts with sufficient product knowledge are more likely than novices to correctly map their usage situations with the product attrib- 
utes based on the attribute information offered by the seller [9].Improving Unattractive Incentive Program will mitigate the impact of Gap of Price Acceptance and Complicated Profit-Sharing Program. The reseller's incentive program is the key driver of the effort payoffs especially when quota was expected achievable [10].

The composite influences of Social Obstacles will affect Product Image and Unattractive Incentive Program. The service quality, brand image and customer satisfaction had a direct relation with customer loyalty [11]. Poor Product Image will cause more Resistance of MultiLevel Selling and Alternative Product Competition; it is related to the brand attachment-the strength of the bond connecting the consumer with the brand, attachment is critical because it should affect behaviors that foster brand profitability and customer lifetime value-which can be used to implicate the brand attitude strength about: 1) the consumers' intentions to perform positive actions in favor of the brand, 2) the actual purchase behaviors, 3) the brand purchase-share among other competing brands, and 4) the need-share among the consumer other expenditures [12].

It is obvious that Gap of Price Acceptance will cause Less Income Support to Self-Care (consumer tends to move spending to living-accessories) and Alternative Product Competition (consumer always seeks for higher cost-performance ratio products) as well. The composite influences of Political Obstacles will cause Less SelfMotivated to resellers. Lacking of Convincing Empirical Cases and Less Self-Motivated will cause more Alternative Product Competition (consumer tends to purchase well-known wellness products).

Figure 3 illustrated the Causal-Loop model. The hypothetical simulations based on the assumptions from the research data showed the following business implications to multi-level selling companies:

- Improving Teaming. To builds a talent pool for different attribute resellers: 1) Channel Development, 2) Product Knowledge Sharing, 3) Experience Sharing, and 4) Selling Process Facilitation.

- Improving Interpersonal Skills. To work with team sand plays the appropriate complement roles. The more highly qualified people are, the more likely they are to participate in learning activities. Learning-byworking and Learning-from-Members to improve their interpersonal competences such as: 1) health, 2) intelligence, 3) empathy, 4) autonomy, 5) judgment, and 6) creativity [13].

- Improving Self-Motivation. To alleviates the political obstacles and makes believe the contribution to society.

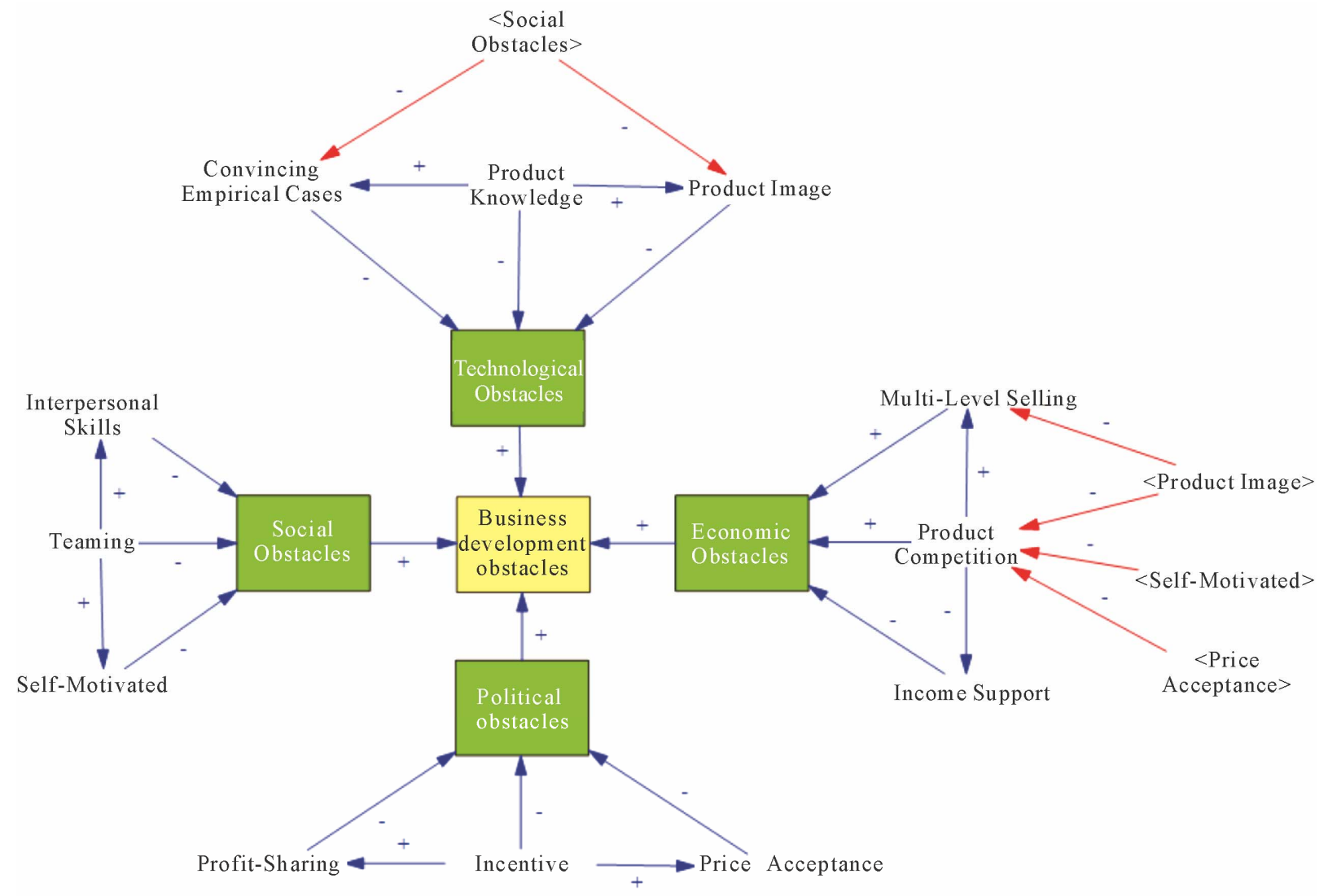

Figure 3. The causal-loop model. 
- Improving Product Knowledge Transferring. To segregate the audiences into different level of groups, provides corresponding materials, and establishes certificate system for each level. Train-the-Trainer approach-based on the lead trainers who are experienced multi-level resellers as a highly skilled core group of instructors to conduct workshops-will help other resellers expanding their channels smoothly.

- Improving Convincing Empirical Cases. To track the selective consumers' health profiles and wellness products intake behaviors to build empirical case studies, evaluates the outcome, and enriches the marketing materials.

- Improving Product Image. To hold more self-care, personal experience, and product knowledge sharing gatherings, discloses successful stories will help product image building.

- Relieving the Skeptical on Multi-level Selling. To reveal the company's vision, outcome of wellness foods, explains why multi-level selling approach was adopted, and compares the differences and similarities with other successful positive companies who adopt the same business model.

- Improving Income Support. To offer a flexible pricing structure for long-term consumers, special programs for individuals who have encountered financial difficulty. This will also improve product image by contribute more on social responsibility.

- Relieving Alternative Product Competition. To reposition the product market segment by competitive pricing and offers more on composite products.

- Improving Price Acceptance. To emphasize the cost structure and the outcome to self-care comparing to competitors' products.

- Improving Incentive Program. To offer the flexible incentive programs by talent contribution instead of just by quantity; encourage resellers to form different combination of selling teams and to maximize reseller's personal achievement.

- Simplifying Profit-Sharing Program. To keep the profit-sharing rules simple and visible by offering reseller personal business web. Resellers can view channel activities and consumers' intake behavior to provide better promptly guidance.

\section{Conclusions}

Promoting wellness foods via multi-level selling model has been a challenge for years to business owners including both companies and the associated resellers. These companies tend to focus more on profit-sharing programs, product knowledge transferring, and morality inspiration training. This paper gives a holistic view about the business model of wellness food companies; it articulates the business complexity in production promo- tion to practitioners. It also combined qualitative research and system dynamics methods to disclose the insight of phenomenon. Different business situation may result different obstacles with various degrees respectively. Lastly, the research subject was pleased for the research findings and looked forward to the next research on the strategy of product pricing and profit-sharing.

Apparently, the self-motivation is the key to the success for the multi-level marketers. The Causality Orientations Theory (COT) describes the individual differences in how people orient to different aspects of the environment in regulating behavior. When autonomyoriented, a person orients to what interests them and acts with congruence. When control-oriented, a person primarily regulates behavior by orienting to social controls and reward contingencies, and when impersonally oriented a person focuses on their lack of personal control or competence [14]. The social obstacles are about autonomy and the political obstacles are control oriented; both can significantly mitigate the impact of the obstacles of a multi-level business development. Although the economy obstacle keeps playing the driver of the motivation, some resellers strongly believed in their products and push the products into the market with confidence. Some customers were moved by the resellers' sincerity and made the purchases.

It was not clear about the pricing strategies and why bonus plans were set in those ways. Both companies' policies on pricing and bonus plans were similar in concept. The latter entrant to this market has the chance to improve these policies. However, it seemed that the younger company did not set these policies with more rational way but by few senior resellers' personal experiences. These policy settings involve intensive financial engineering studies.

Another interesting finding of this research is that both research subjects' information systems were poor. The resellers were hardly able to take advantage of information technologies to facilitate the selling processes. For example, the information technology can make the reward mechanisms much easier in exploiting the indirect referrals [15]. Both official web sites lacked of enough information for newbies or potential customers to understand either the product benefits or the complex bonus plans.

\section{REFERENCES}

[1] R. F. Wilson, "The Six Simple Principles of Viral Marketing,” Web Marketing Today, Vol. 70, 2000, p. 232.

[2] M. R. Subramani and B. Rajagopalan, "KnowledgeSharing and Influence in Online Social Networks via Viral Marketing," Communications of the ACM, Vol. 46, No. 12, 2003, pp. 300-307. doi:10.1145/953460.953514

[3] C. W. N. Mack, K. M. MacQueen, G. Guest and E. Namey, 
“Qualitative Research Methods: A Data Collector’s Field Guide," 2012.

http://www.fhi360.org/en/RH/Pubs/booksReports/QRM_ datacoll.htm

[4] D. R. Thomas, "A General Inductive Approach for Analyzing Qualitative Evaluation Data," American Journal of Evaluation, Vol. 27, No. 2, 2006, pp. 237-246. doi:10.1177/1098214005283748

[5] M. K. Jain, “An Efficient Expert System Generator for Qualitative Feed-Back Loop Analysis,” BRAIN: Broad Research in Artificial Intelligence and Neuroscience, Vol. 3, No. 1, 2012, pp. 5-18.

[6] J. W. Forrester, "System Dynamics, Systems Thinking, and Soft OR," System Dynamics Review, Vol. 10, No. 2, 1994, pp. 245-256. doi:10.1002/sdr.4260100211

[7] E. Salas, N. J. Cooke and M. A. Rosen, "On Teams, Teamwork, and Team Performance: Discoveries and Developments," Human Factors: The Journal of the Human Factors and Ergonomics Society, Vol. 50, No. 3, 2008, pp. 540-547. doi:10.1518/001872008X288457

[8] E. L. Deci and R. M. Ryan, "Self-Determination Theory: A Macrotheory of Human Motivation, Development, and Health," Canadian Psychology/Psychologie Canadienne, Vol. 49, No. 3, 2008, pp. 182-185. doi:10.1037/a0012801

[9] Y. Chen and J. Xie, “Online Consumer Review: Word-ofMouth as a New Element of Marketing Communication Mix,” Management Science, Vol. 54, No. 3, 2010, pp.
477-491. doi:10.1287/mnsc.1070.0810

[10] S. Misra and H. Nair, "The Dynamic Consequences of Incentive Schemes: Evidence from Salesforce Compensation," 2009.

http://www.stanford.edu/group/SITE/SITE_2009/segment _2/2009_s2_papers/nair.pdf

[11] K. H. Liao and M. F. Hsieh, "Statistic Exploring the Casual Relationships between Service Quality, Brand Image, Customer Satisfaction and Customer Loyalty on the Leisure Resort Industry,” 2011.

http://irssm.upnyk.ac.id/userfiles/file/papers/063.pdf

[12] C. W. Park, D. MacInnis, J. Priester, A. Eisingerich and D. Iacobucci, "Brand Attachment and Brand Attitude Strength: Conceptual and Empirical Differentiation of Two Critical Brand Equity Drivers,” Journal of Marketing, Vol. 74, No. 6, 2010, pp. 1-17. doi:10.1509/jmkg.74.6.1

[13] B. J. Alge, M. T. Gresham, R. L. Heneman, J. Fox and R. McMasters, "Measuring Customer Service Orientation Using a Measure of Interpersonal Skills: A Preliminary Test in a Public Service Organization,” Journal of Business and Psychology, Vol. 16, No. 3, 2002, pp. 467-476. doi:10.1023/A:1012833326181

[14] R. Ryan, "Self-Determination Theory and Wellbeing," Social Psychology, Vol. 84, 2009, pp. 822-848.

[15] Y. Emek, R. Karidi, M. Tennenholtz and A. Zohar, "Mechanisms for Multi-Level Marketing," 2011. http://www.eecs.harvard.edu/cs286r/papers/rewards.pdf 